\title{
Dimension of chronic hepatitis C virus in HIV-infected patients in the interferon-free era: an overview from south Spain
}

\author{
A. Rivero-Juarez ${ }^{1}$ A. Gutierrez-Valencia ${ }^{2}$ - M. Castaño ${ }^{3} \cdot$ D. Merino ${ }^{4} \cdot$ K. Neukam ${ }^{5}$ \\ M. J. Ríos-Villegas ${ }^{6}$ • M. A. Lopez-Ruz ${ }^{7}$ • P. Jiménez-Aguilar ${ }^{8}$ • M. Marquez ${ }^{9}$. \\ A. Collado ${ }^{10}$ - A. Gomez-Vidal ${ }^{11}$ - J. Hernandez-Quero ${ }^{12} \cdot$ F. Tellez $^{13}$. $^{1}$ \\ E. Fernandez-Fuertes ${ }^{1,2,3,4,5,6,7,8,9,10,11,12,13,14}$ - A. Rivero ${ }^{1}$ - L. F. López-Cortés ${ }^{2}$ - on \\ behalf of Grupo para el Estudio de las Hepatitis Víricas (HEPAVIR) de la Sociedad \\ Andaluza de Enfermedades Infecciosas (SAEI)
}

Received: 21 July 2015 / Accepted: 20 August 2015 /Published online: 5 September 2015

(C) The Author(s) 2015. This article is published with open access at Springerlink.com

\begin{abstract}
The implementation of hepatitis C (HCV) directacting antiviral drugs is prioritized in several populations in which its application provides the most immediate and impactful benefit. In this scenario, a precise knowledge of the situation of human immunodeficiency virus (HIV)/HCV chronic co-infection is required to adequately address this disease. This cross-sectional study was performed in 21 hospitals in Andalusia (Spain). The study population consisted of HIVinfected patients with an active HCV chronic infection who
\end{abstract}

were not receiving HCV treatment at the time of inclusion. A total of 13,506 HIV-infected patients were included in the study. Of them, 2561 (18.9 \%) presented chronic HCV infection. The majority of the patients included were on highly active antiretroviral therapy (HAART; $96.2 \%$ ), showed plasma levels with an undetectable HIV viral load (92.5\%), and had a good immunological status (median CD4+ cell count of 486 cells $/ \mathrm{mL}$ ). The HCV genotype distribution was as follows: $58.1 \%$ were genotype $1,1.1 \%$ were genotype 2 ,

A. Rivero-Juarez and A. Gutierrez-Valencia contributed equally to this work.

A. Rivero-Juarez

arjvet@gmail.com

$\triangle$ A. Rivero

ariveror@gmail.com

1 Unidad Clínica de Enfermedades Infecciosas, Instituto Maimonides de Investigación Biomédica de Córdoba (IMIBIC), Universidad de Córdoba, Hospital Universitario Reina Sofía, Avda. Menendez Pidal s/n, 14004 Cordoba, Spain

2 Unidad Clínica de Enfermedades Infecciosas, Microbiología y Medicina Preventiva, Instituto de Biomedicina de Sevilla (IBiS), Hospital Universitario Virgen del Rocío/CSIC/Universidad de Sevilla, Seville, Spain

3 Unidad Clínica de Enfermedades Infecciosas, Hospital Regional Universitario Carlos Haya, Málaga, Spain

4 Unidad Clínica de Enfermedades Infecciosas, Complejo Hospitalario Universitario de Huelva, Huelva, Spain

5 Unidad Clínica de Enfermedades Infecciosas y Microbiología, Instituto de Biomedicina de Sevilla (IBiS), Hospital Universitario de Valme, Seville, Spain
6 Unidad Clínica de Enfermedades Infecciosas y Microbiología, Hospital Universitario Virgen Macarena, Seville, Spain

7 Unidad Clínica de Enfermedades Infecciosas y Microbiología, Hospital Universitario Virgen de las Nieves, Granada, Spain

8 Unidad Clínica de Enfermedades Infecciosas, Hospital Universitario Puerto Real, Cádiz, Spain

9 Unidad Clínica de Enfermedades Infecciosas y Microbiología, Hospital Regional Universitario Virgen de la Victoria, Málaga, Spain

10 Unidad Clínica de Enfermedades Infecciosas, Complejo Hospitalario Torrecárdenas, Almería, Spain

11 Unidad Clínica de Enfermedades Infecciosas, Complejo Hospitalario de Jaén, Jaén, Spain

12 Unidad Clínica de Enfermedades Infecciosas, Hospital Universitario San Cecilio, Granada, Spain

13 Unidad Clínica de Enfermedades Infecciosas y Microbiología, Hospital La Línea, AGS Campo de Gibraltad, Cádiz, Spain

14 Unidad de Medicina Tropical, Hospital de Poniente, Almería, Spain 
$16.1 \%$ were genotype 3 , and $22.1 \%$ were genotype $4(2.6 \%$ were missing data). In total, $24.8 \%$ of the patients showed liver fibrosis stage F0-F1, $27.9 \%$ showed stage F2, $16.7 \%$ showed stage F3, and $21 \%$ showed stage F4 (9.6\% were missing data). With regards to previous HCV treatment experiences, $68.05 \%$ of the patients were naïve and $31.95 \%$ had failed to respond to a previous treatment. The burden of HCV/HIV co-infected patients in our population was reported as one in five HIV-infected patients requiring $\mathrm{HCV}$ treatment. The implementation of extra resources to face this important health challenge is mandatory.

\section{Introduction}

The introduction of direct-acting antiviral (DAA) drugs has supposed a significant improvement in the prognosis of the hepatitis $\mathrm{C}$ virus (HCV) infection [1-6]. This important advancement has substantially increased the likelihood of achieving a sustained virological response (SVR) using shorter and safer therapies [1-6]. In consequence, the target population to be treated has expanded significantly because the lack of clinical contraindications, mainly due to interferon (IFN), is no longer a cornerstone of $\mathrm{HCV}$ treatment [7, 8].

It is estimated that $\sim 3 \%$ of the world's population $(\sim 170$ million people) is chronically infected with $\mathrm{HCV}$, of which approximately 350,000 die annually from complications related to cirrhosis or hepatocellular carcinoma [9]. Among those particularly affected is the group of patients with concurrent human immunodeficiency virus (HIV) infection because both infections share identical routes of transmission [10]. The reduction of morbidity and mortality and the increased survival in patients with HIV infection, which is attributable to the effectiveness of antiretroviral therapy, has currently allowed HCV chronic liver disease to become a major cause of hospitalizations and mortality in these patients because survival is significantly lower, regardless of other prognostic markers of cirrhosis, compared to mono-infected patients [11-18]. Therefore, the HIV-infected population is a high-priority population that must receive immediate treatment against chronic HCV infection [7].

In this scenario, precise knowledge of the situation of the HIV/HCV chronic co-infection would facilitate the adequate provision of personal and material resources required to adequately address this disease in each center and in the community as a whole. Thus, the aim of our study was to evaluate the current situation of HCV chronic infection in HIV co-infected patients. Given these drawbacks, we designed a study with the objective of determining the dimension of the HCV chronic infection among HIV-infected patients.

\section{Methods}

\section{Study design and source of information}

This prospective cross-sectional study was conducted in two phases to address two specific objectives. During the first phase, an inquiry was performed in 21 hospitals that conformed to the HIV health care of the territory (Fig. 1), with the objective of calculating the total HIVinfected patient population. Once all the patients were obtained at the end of the first phase, the second phase selected hospitals with a significant number of patients in active follow-up, excluding those that attended $<100$ patients. The objective of the second phase was to identify the number of HIV-infected patients with active HCV chronic infection. To assess this objective, a specific electronic form (database) was facilitated to each hospital to record specific clinical data of each chronic HCV-infected patient (defined as the study population).

The study was designed, managed, and analyzed by all the authors who reviewed the study data, guaranteed the reliability of the data, conducted the study in accordance with the protocol followed, and approved the decision to submit the manuscript for publication.

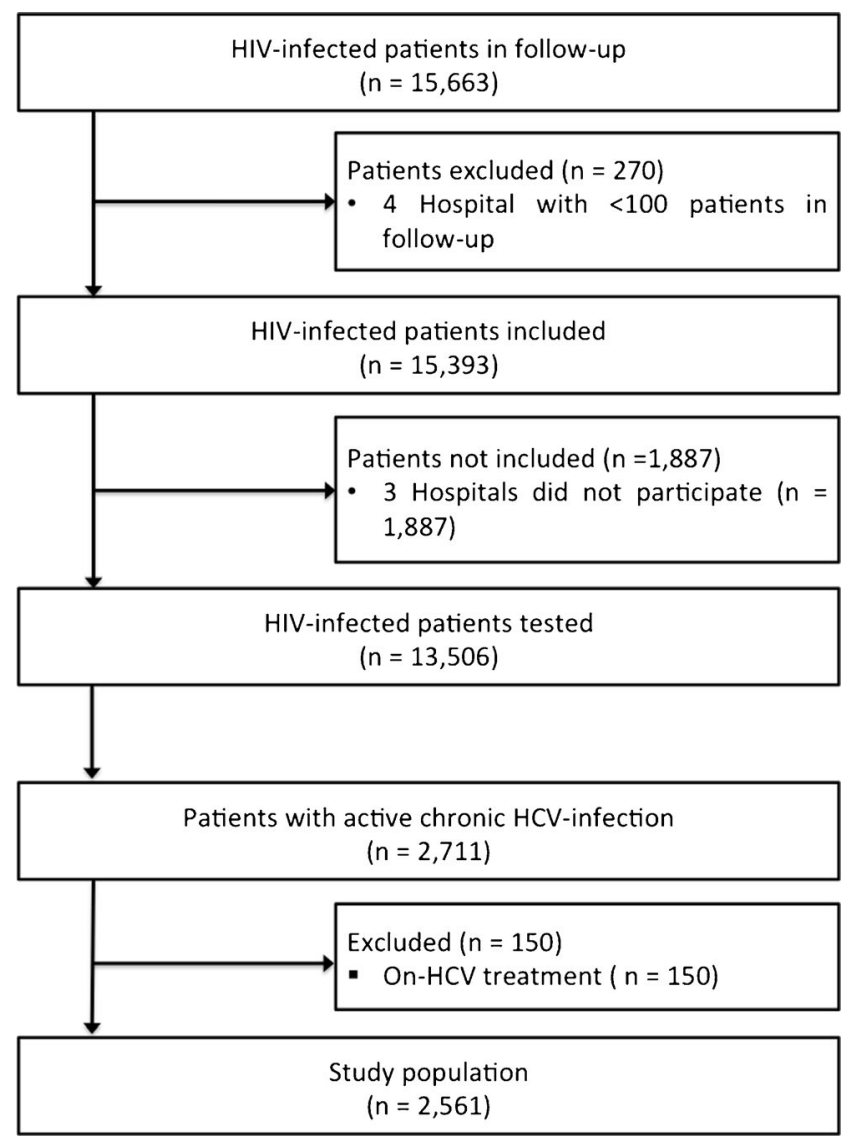

Fig. 1 Patient flow diagram 


\section{Setting}

The study was performed in Andalusia, Spain (south Europe) during June and December 2014. Andalusia is a south Europe region with universal health coverage and a population of 8.3 million people. Andalusia features 21 hospitals encompassing the entire territory that attend HIV-infected patients.

\section{Participants}

The study population consisted of HIV-infected patients with an active $\mathrm{HCV}$ chronic infection, which was identified during the second phase of the study. This population was defined as: (i) patients with detectable plasmatic HCVRNA at the moment of inclusion and (ii) patients who were not on HCV therapy at the moment of inclusion in the study. Consequently, the data of patients with undetectable HCV viral loads, including those with SVR or with spontaneous viral clearance, were not collected in the study.

\section{Variable collection and definitions}

The data were collected in electronic forms (database), including the participant, demographic, clinical, and virological characteristics. These data included age, gender, risk for $\mathrm{HCV}$ infection, current use of antiretroviral therapy (yes or no), current $\mathrm{CD} 4+$ cell count (cells $/ \mathrm{mL}$ ), current plasmatic HIV viral load (copies $/ \mathrm{mL}$ ), current plasmatic HCV viral load (IU/mL), HCV genotype/subtype, current liver fibrosis stage, Child-Pugh-Turcotte (Child-PT) score (A, B, or C), history of HCV therapy, and current use of HCV therapy.

An undetectable HIV viral load was defined as an HIV-1 RNA viral load of less than 50 copies per mL, using RT-PCR (Cobas TaqMan; Roche Diagnostic Systems Inc., Pleasanton, CA, USA). Liver fibrosis staging was performed by liver biopsy (following the METAVIR fibrosis score) and/or liver transient elastography (FibroScan; Echosens, Paris, France). The liver fibrosis stages were grouped as follows: (i) F0-F1 METAVIR fibrosis score or LSM $<7.2 \mathrm{kPa}$; (ii) F2 METAVIR fibrosis score or LSM 7.2-8.9 kPa; (iii) F3 METAVIR fibrosis score or LSM 9-14.5; and (iv) F4 METAVIR fibrosis score or $\mathrm{LSM} \geq 14.6 \mathrm{kPa}$. In the patients with liver cirrhosis, the ChildPT score was calculated using the parameters hepatic encephalopathy, ascites, total bilirubin, serum albumin, and prothrombin time. According to the value obtained, the patients were classified as follows: A (5-6 points), $\mathrm{B}$ (7-8 points), or $\mathrm{C}$ ( $>9$ points).

The study data were transcribed onto data collection forms in which one code was assigned to each patient: the ID code. Only the physician directly responsible for each patient and/or authorized personnel had access to the medical history of the patients according to Law 15/1999 of December 13,
Protection of Personal Data. This confidential information is the exclusive property of the physician directly responsible for patient care and may not be used except for conducting this study. The information created during the conduct of this clinical study is considered confidential and is/ will be used by researchers in relation to the objectives of the study.

\section{Statistical methods}

The elaboration of the manuscript has been performed following the Strengthening the Reporting of Observational Studies in Epidemiology (STROBE) recommendations. For the purpose of the study, those patients on HCV treatment at the moment of inquiry were excluded from the analysis. The descriptive statistics of the patients were reported. The continuous variables were summarized as the median and interquartile range (IQR); meanwhile, the categorical variables were expressed as frequencies/number of cases and percentages. The categorical variables were compared using the Chisquare test or Fisher's exact test if the expected frequency of any group was lower than $5 \%$.

The principal analysis consisted of the patient distribution according to $\mathrm{HCV}$ genotype and liver fibrosis stage. A secondary analysis was performed in which the HCV genotype and liver fibrosis distribution were reported by sorting the patients according to previous experience with HCV treatment (including Peg-IFN/RBV and DAAbased regimens).

\section{Ethics issues}

This study was conducted according to the principles of Good Clinical Practice (Ministry of Health, Royal Decree 223/2004 of 6 February) and the Declaration of Helsinki; the protection of personal data is guaranteed in accordance with Law 15/ 1999 of 13 December on the Protection of Personal Data and Royal Decree 1720/2007 of 21 December. The study did not require informed consent because the patients were not directly interviewed, and completely anonymous information from existing records was collected, ensuring the protection of personal data in accordance with Law 15/1999 of 13 December on Personal Data Protection.

The study coordinator presented the study protocol (protocol code: HEP-COI-1-2014) to the Coordinating Ethics Committee of Biomedical Research of Andalusia for evaluation and obtained approval (05/14). Those responsible for the providers of health services where the study occurred were given a copy of the protocol and the documents evidencing approval by the Ethics Committee in accordance with the procedures and legal requirements. 


\section{Results}

\section{Population tested}

After the first phase, a total of 15,663 HIV-infected patients were obtained in the prospective follow-up in our media (HIV prevalence: 1.8 per 1000 inhabitants) (Fig. 1). For the second phase, four hospitals were excluded because they had less than 100 patients in their follow-up of an HIV-infected population $(n=270)$. Consequently, 15,393 HIV-infected patients ( $98.3 \%$ of the total population in follow-up) comprised the target population of the study.

Fourteen of the 17 hospitals included in the second phase of the study agreed to participate (Fig. 1). Thus, the study target population consisted of 13,506 patients $(87.4 \%$ of the target population). Of this population, the presence of active chronic $\mathrm{HCV}$ infection was reported in 2711 patients (20.5\%), of which 150 patients $(5.5 \%)$ were on $\mathrm{HCV}$ treatment at inclusion and were excluded from the analysis according to the study protocol. Consequently, 2561 (18.9 \%) HIV/HCV chronically infected patients constituted the study population.

\section{Patients}

The baseline demographic and clinical characteristics are shown in Table 1. The majority of the patients included were on highly active antiretroviral therapy (HAART; $96.2 \%$ ), showed undetectable plasma HIV viral loads (92.5\%), and had a good immunological status (median CD4+ cell count: 486 cells $/ \mathrm{mL}$ [308-697]). The most prevalent HCV genotype was genotype 1 (58.1\%), with HCV subtype 1a being predominant in our population (38.3\%). In total, $21 \%$ of the patients $(n=538)$ showed liver cirrhosis, with a Child-PT score of $\mathrm{A}$ in $65.8 \%$ of the patients in this subset.

In regards to previous HCV treatment (Table 1), $68.05 \%$ of the patients had not received previous therapy and, consequently, $31.95 \%$ had failed to respond to at least one previous $\mathrm{HCV}$ treatment. Among the 818 patients with a previous treatment failure, $60.7 \%$ of patients did not complete the full course of therapy because of the absence of a viral response, $16.6 \%$ experienced a viral relapse after a full course of therapy, and $22.7 \%$ voluntarily dropped out of therapy or withdrew because of adverse events.

\section{Distribution according to $\mathrm{HCV}$ genotype and liver fibrosis}

The patient distribution according to HCV genotype and liver fibrosis stage is shown in Fig. 2. The liver fibrosis stage appeared to be consistent across HCV genotypes. The highest percentage of F4 patients was found among HCV genotype 3 patients $(24.4 \%)$. The highest percentage of $\mathrm{F} 2$ patients was found in those bearing HCV genotype 4 (31.3\%) but was not statistically significant. Among those patients with an unavailable HCV genotype ( $n=65), 26.1 \%$ were classified as F4 liver fibrosis stage. The percentage of missing liver fibrosis stages was greater than $10 \%$ in the patients bearing HCV genotypes 2, 3, and 4.

\section{Distribution of HCV genotype and liver fibrosis according to previous $\mathrm{HCV}$ treatment}

The secondary analysis was performed to assess the HCV genotype and liver fibrosis stage distribution according to previous HCV therapy (Fig. 3). This distribution among previously untreated and treatment-experienced patients is shown in Fig. 3a, b, respectively. Globally, the percentage of F4 patients was the greatest among treatment-experienced patients than previously untreated patients $(30.4 \%$ vs. $16.6 \%$, $p<0.001)$. In contrast, the percentage of F0-F1 patients was higher among treatment-naïve patients $(28.3 \%)$ than in treatment-experienced patients $(16.9 \%)(p<0.001)$. When this association was analyzed in each treatment experience group according to $\mathrm{HCV}$ genotype, no statistical association was found.

\section{Discussion}

This is the first study showing the dimensions of HCV chronic infection in HIV-infected patients by targeting one of the largest HIV population samples. The burden of HCV/HIV coinfected patients in our population reported that at least one in five HIV-infected patients required HCV treatment. Therefore, the implementation of extra resources to face this important health challenge is mandatory.

In Europe, the most common HCV genotype is genotype 1 (specifically, genotype 1b), followed by genotype 3; there is a relatively low frequency of genotypes 2 and 4 in the overall HCV population [19]. Nevertheless, if the HCV genotype distribution is focused among HIV co-infected patients, this appears to change. HCV genotypes appear to have strong epidemiological behavior; in other words, they have a close relationship with HIV infection/transmission [19, 20]. The main route of HCV transmission in HIV-infected patients has been illegal injection drug use (IDU) [21]; in our study, this route represented $87.7 \%$ of the transmission. In this context, the introduction of several HCV genotypes into networks of IDU in Europe, such as genotypes 1a and 4 [19], has altered the HCV genotype distribution in this population subset. This point was confirmed in our study, in which HCV genotype 1 (specifically, genotype 1a) and HCV genotype 4 were the most prevalent, as opposed to HCV genotype 3. This particular HCV genotype distribution converted these patients to "difficult to treat patients", mainly because of the significantly low response rate to Peg-IFN/RBV therapy compared to HCV genotypes 2 and 3 [22]. 
Table 1 Baseline demographic and clinical characteristics of the study patients

\begin{tabular}{|c|c|c|c|c|c|c|}
\hline Characteristic & Global $(n=2561)$ & G-1a $(n=572)$ & $\mathrm{G}-1 \mathrm{~b}(n=329)$ & G-2 $(n=28)$ & G-3 $(n=413)$ & G-4 $(n=565)$ \\
\hline Age, years ${ }^{\mathrm{a}}$ & $49(45-52)$ & $48(44-53)$ & $49(45-52)$ & $31(26-57)$ & $49(45-52)$ & $48(45-52)$ \\
\hline \multicolumn{7}{|l|}{ Age range, no. $(\%)$} \\
\hline$<40$ & $133(5.3)$ & $35(6.1)$ & $18(5.4)$ & $2(7.1)$ & $18(4.3)$ & $32(5.6)$ \\
\hline $41-50$ & $1352(52.8)$ & $304(53.1)$ & $149(45.2)$ & $11(39.2)$ & $207(50.1)$ & $317(56.1)$ \\
\hline $51-60$ & $1017(39.7)$ & $220(38.4)$ & $148(44.9)$ & $14(50)$ & $170(41.1)$ & $206(36.4)$ \\
\hline$>60$ & $59(2.2)$ & $13(2.4)$ & $14(4.5)$ & $1(3.7)$ & $17(4.5)$ & $10(1.9)$ \\
\hline \multicolumn{7}{|l|}{ Gender, no. (\%) } \\
\hline Male & $2118(82.7)$ & $471(82.3)$ & $283(86)$ & $23(82.1)$ & $327(79.1)$ & $454(80.3)$ \\
\hline Female & $443(17.3)$ & $101(17.7)$ & $46(14)$ & $5(17.9)$ & $86(20.9)$ & $111(19.7)$ \\
\hline \multicolumn{7}{|l|}{ Risk group for HCV infection, no. (\%) } \\
\hline IDU & $2248(87.7)$ & $499(87.2)$ & $279(84.8)$ & $24(85.7)$ & $349(84.5)$ & $495(87.6)$ \\
\hline Heterosexual & $219(8.5)$ & $42(7.5)$ & $32(9.7)$ & $3(10.7)$ & $49(11.8)$ & $54(9.5)$ \\
\hline Homosexual & $75(2.9)$ & $21(3.6)$ & $14(4.2)$ & $1(3.6)$ & $12(2.9)$ & $12(2.1)$ \\
\hline Blood derived & $19(0.9)$ & $9(1.7)$ & $3(1.3)$ & 0 & $1(0.8)$ & $2(0.8)$ \\
\hline \multicolumn{7}{|l|}{ HAART, no. (\%) } \\
\hline Receiving & $2468(96.2)$ & $556(97.2)$ & $317(96.3)$ & $27(96.4)$ & $394(95.3)$ & $542(95.9)$ \\
\hline Non-receiving & $93(3.8)$ & $16(2.8)$ & $12(3.7)$ & $1(3.6)$ & $19(4.7)$ & $23(4.1)$ \\
\hline \multicolumn{7}{|l|}{ HIV viral load, no. $(\%)^{b}$} \\
\hline Undetectable & $2370(92.5)$ & $527(92.1)$ & $301(91.4)$ & $27(96.4)$ & $383(92.7)$ & $521(92.2)$ \\
\hline Detectable & $191(7.5)$ & $38(7.9)$ & $21(8.6)$ & $1(3.6)$ & $26(7.3)$ & $42(7.8)$ \\
\hline $\mathrm{CD} 4+$ total count, cells $/ \mathrm{mL}^{\mathrm{a}}$ & $486(308-697)$ & $470(328-702)$ & $502(304-694)$ & $400(278-699)$ & $452(321-693)$ & $513(394-721)$ \\
\hline \multicolumn{7}{|l|}{ CD4+ cell grading, no. $(\%)$} \\
\hline$<200$ cells $/ \mathrm{mL}$ & $339(13.2)$ & $83(14.6)$ & $31(9.5)$ & $1(3.6)$ & $62(15.1)$ & $64(11.4)$ \\
\hline$\geq 200$ cells $/ \mathrm{mL}$ & $2222(86.8)$ & $489(85.4)$ & $298(90.5)$ & $27(96.4)$ & $351(84.9)$ & $501(88.6)$ \\
\hline \multicolumn{7}{|l|}{ HCV genotype, no. (\%) } \\
\hline Genotype 1 & $1490(58.1)$ & - & - & - & - & - \\
\hline Genotype 2 & $28(1.1)$ & - & - & - & - & - \\
\hline Genotype 3 & $413(16.1)$ & - & - & - & - & - \\
\hline Genotype 4 & $565(22.1)$ & - & - & - & - & - \\
\hline Non-genotyped & $65(2.6)$ & - & - & - & - & - \\
\hline \multicolumn{7}{|l|}{ HCV genotype 1 subtype, no. (\%) } \\
\hline Genotype 1a & $572(38.3)$ & - & - & - & - & - \\
\hline Genotype $1 b$ & $329(22.1)$ & - & - & - & - & - \\
\hline Other genotype ${ }^{c}$ & $41(2.7)$ & - & - & - & - & - \\
\hline Non-subtyped & $552(36.9)$ & - & - & - & - & - \\
\hline \multicolumn{7}{|l|}{ Liver fibrosis stage, no. $(\%)^{\mathrm{d}}$} \\
\hline F0-F1 & $636(24.8)$ & $147(25.7)$ & $79(24)$ & $8(28.5)$ & $89(21.5)$ & $145(25.6)$ \\
\hline $\mathrm{F} 2$ & $716(27.9)$ & $180(31.4)$ & $103(31.3)$ & $6(21.4)$ & $83(20.1)$ & $177(31.3)$ \\
\hline F3 & $428(16.7)$ & $81(14.1)$ & $52(15.8)$ & $5(17.8)$ & $81(19.6)$ & $95(16.8)$ \\
\hline $\mathrm{F} 4$ & $538(21)$ & $121(21.1)$ & $66(20.1)$ & $4(14.2)$ & $101(24.4)$ & $87(15.5)$ \\
\hline Not staged & $243(9.6)$ & $43(7.5)$ & $29(8.8)$ & $5(17.5)$ & $59(14.4)$ & $61(10.8)$ \\
\hline \multicolumn{7}{|l|}{ Child-PT, no. (\%) } \\
\hline A & $345(65.8)$ & $74(61.5)$ & $43(65.1)$ & $4(100)$ & $65(64.3)$ & $49(56.3)$ \\
\hline $\mathrm{B}$ & $53(9.8)$ & $10(8.2)$ & $4(6)$ & 0 & $14(13.8)$ & $10(11.4)$ \\
\hline $\mathrm{C}$ & $17(3.1)$ & $8(6.6)$ & $1(1.5)$ & 0 & $1(1.2)$ & $3(2.5)$ \\
\hline Not available & $123(21.3)$ & $29(23.7)$ & $18(27.4)$ & 0 & $21(20.7)$ & $26(29.8)$ \\
\hline \multicolumn{7}{|c|}{ HCV therapy previous experience, no. (\%) } \\
\hline Naïve & $1743(68.05)$ & $379(66.2)$ & $207(62.9)$ & $22(78.5)$ & $269(65.1)$ & $384(67.9)$ \\
\hline Non-responder to Peg-IFN/RBV & $743(29.01)$ & $167(29.1)$ & $102(31)$ & $6(21.5)$ & $143(34.6)$ & $178(31.5)$ \\
\hline
\end{tabular}


Table 1 (continued)

\begin{tabular}{|c|c|c|c|c|c|c|}
\hline Characteristic & Global $(n=2561)$ & G-1a $(n=572)$ & $\mathrm{G}-1 \mathrm{~b}(n=329)$ & G-2 $(n=28)$ & $\mathrm{G}-3(n=413)$ & G-4 $(n=565)$ \\
\hline Non-responder to DAA-based regimen & $75(2.94)$ & $26(4.7)$ & $20(6.1)$ & 0 & $1(0.3)$ & $3(0.6)$ \\
\hline \multicolumn{7}{|l|}{ Previous response to Peg-IFN/RBV, no. (\%) } \\
\hline Non-responders & $451(60.7)$ & $93(55.6)$ & $53(51.9)$ & $6(100)$ & $35(24.4)$ & $130(73)$ \\
\hline Viral relapse & $123(16.5)$ & $21(12.5)$ & $19(18.6)$ & 0 & $63(44)$ & $25(14)$ \\
\hline Therapy withdrawn ${ }^{\mathrm{e}}$ & $169(22.8)$ & $53(31.9)$ & $30(29.5)$ & 0 & $45(31.6)$ & $23(13)$ \\
\hline \multicolumn{7}{|l|}{ Previous response to DAA-based regimen, no. (\%) } \\
\hline Non-responders & $46(61.3)$ & $5(19.2)$ & $7(37.1)$ & 0 & 0 & $2(66.6)$ \\
\hline Viral relapse & $13(17.3)$ & $17(65.3)$ & $11(54.2)$ & 0 & $1(100)$ & 0 \\
\hline Therapy withdrawn ${ }^{\mathrm{e}}$ & $16(21.4)$ & $4(15,5)$ & $2(18.7)$ & 0 & 0 & $1(33.4)$ \\
\hline IFN-based therapy contraindication, no. $(\%)^{\mathrm{f}}$ & $198(7.7)$ & $41(7.1)$ & $26(7.9)$ & $1(3.5)$ & $43(10.4)$ & $33(5.8)$ \\
\hline Alcohol abuse, no. $(\%)^{\mathrm{g}}$ & $55(2.1)$ & $16(2.7)$ & $6(1.8)$ & $1(3.5)$ & $7(1.6)$ & $8(1.4)$ \\
\hline
\end{tabular}

Number of cases (no.); percentage (\%); genotype 1a (G-1a); genotype 1b (G-1b); genotype 2 (G-2); genotype 3 (G-3); genotype 4 (G-4); hepatitis C virus (HCV); injecting drug user (IDU); highly active antiretroviral therapy (HAART); human immunodeficiency virus (HIV); milliliter (mL); Child-PughTurcotte score (Child-PT); pegylated interferon plus ribavirin (Peg-IFN/RBV); direct-acting antiviral (DAA) agent

${ }^{a}$ Expressed as the median (interquartile range)

${ }^{\mathrm{b}}$ Undetectable plasmatic HIV viral loads were defined as HIV-RNA $<50 \mathrm{IU} / \mathrm{mL}$

${ }^{\mathrm{c}}$ Genotypes $1 \mathrm{c}$ or $1 \mathrm{a} / \mathrm{b}$

${ }^{\mathrm{d}}$ Liver fibrosis was measured by liver biopsy or liver stiffness

${ }^{\mathrm{e}}$ Patients who voluntarily dropped out of therapy or withdrew because of adverse events

${ }^{\mathrm{f}}$ Including patients with severe adverse events to previous interferon-based therapy, advanced or decompensated liver cirrhosis, oncological patients, those with severe renal impairment, uncontrolled psychiatric disorders, or autoimmune diseases

${ }^{g}$ Defined as a daily alcohol ingestion $>100 \mathrm{mg}$

IDU HCV-transmitted patients, specifically those coinfected with HIV, show a faster liver fibrosis progression to liver cirrhosis and end-stage liver disease [23, 24]. Mainly because of this reason, historically, HIV-infected patients have constituted the worst subset of HCV-infected patients. However, this axiom was established during the era in which HCV therapeutic management was insufficient in terms of efficacy and safety. Taking this into account and considering the availability of more effective antiviral drugs against HCV and HIV infection, this situation may have changed. In our study, the majority of patients were on HAART (96.2\%), showed undetectable HIV viral loads (92.5\%), and had a relatively good immunological situation $(406 \mathrm{CD} 4+$ cells/ $\mathrm{mL}$ median value). This population (likely comparable to the population followed in other countries with universal health care coverage) matched the population included in clinical trials in which the safety and efficacy of HCV DAA drugs were tested in HIV-infected patients. In these trials, the SVR rates obtained were similar to those obtained in non-HIV coinfected patients, across liver fibrosis stages, genotype, or
Fig. 2 Liver fibrosis stage distribution according to hepatitis $\mathrm{C}$ virus (HCV) genotype in the total population included. The distribution is expressed as the cumulative percentage in each $\mathrm{HCV}$ genotype column. HCV genotype $1(G-1), \mathrm{HCV}$ genotype $2(G-2)$, HCV genotype $3(G-3)$, HCV genotype $4(G-4), \mathrm{HCV}$ genotype undetermined $(N G)$, liver fibrosis stage undetermined $(N / A)$

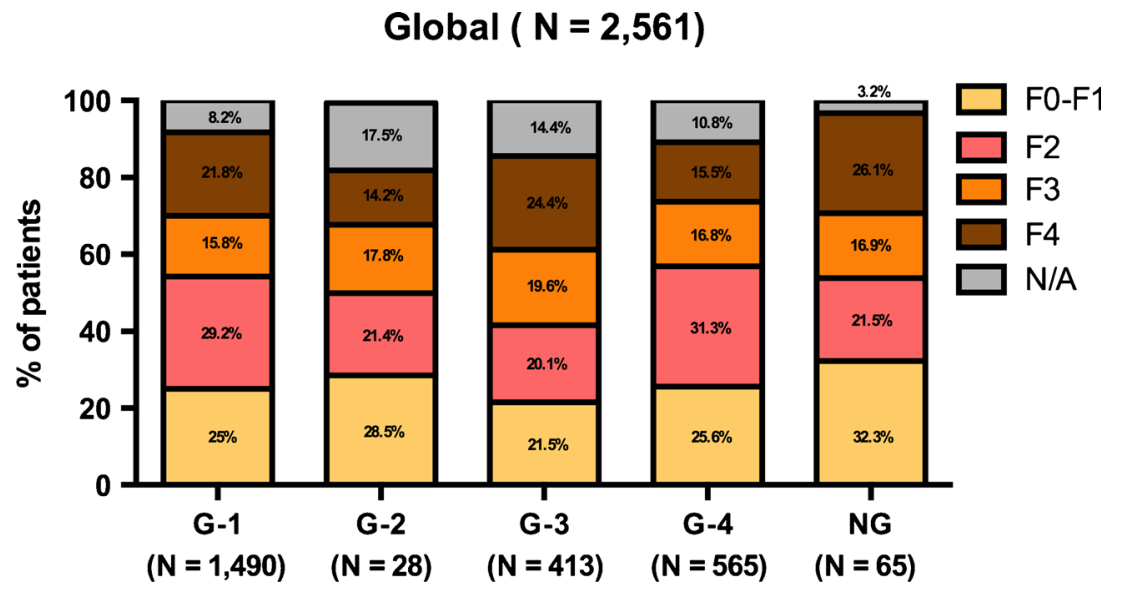


Fig. 3 Liver fibrosis stage distribution according to $\mathrm{HCV}$ genotype in treatment-naïve (a) and treatment-experienced patients (b). The patients with previous treatment failure to pegylated-interferon plus ribavirin (Peg-IFN/RBV) or directacting antiviral (DAA) drugs therapy were grouped for the analysis. The distribution is expressed as the cumulative percentage in each HCV genotype column. HCV genotype $1(G-1)$, HCV genotype 2 (G-2), HCV genotype $3(G-3)$, HCV genotype $4(G-4)$, HCV genotype undetermined $(N G)$, liver fibrosis stage undetermined $(N / A)$
Treatment naïve

$(N=1,743)$

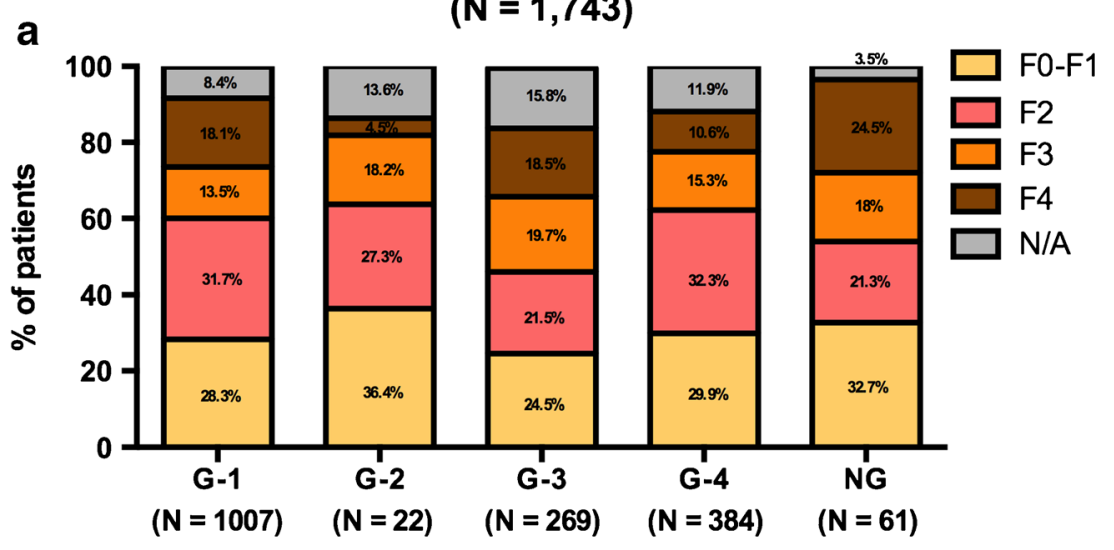

Treatment Experienced $(\mathbf{N}=\mathbf{8 1 8})$

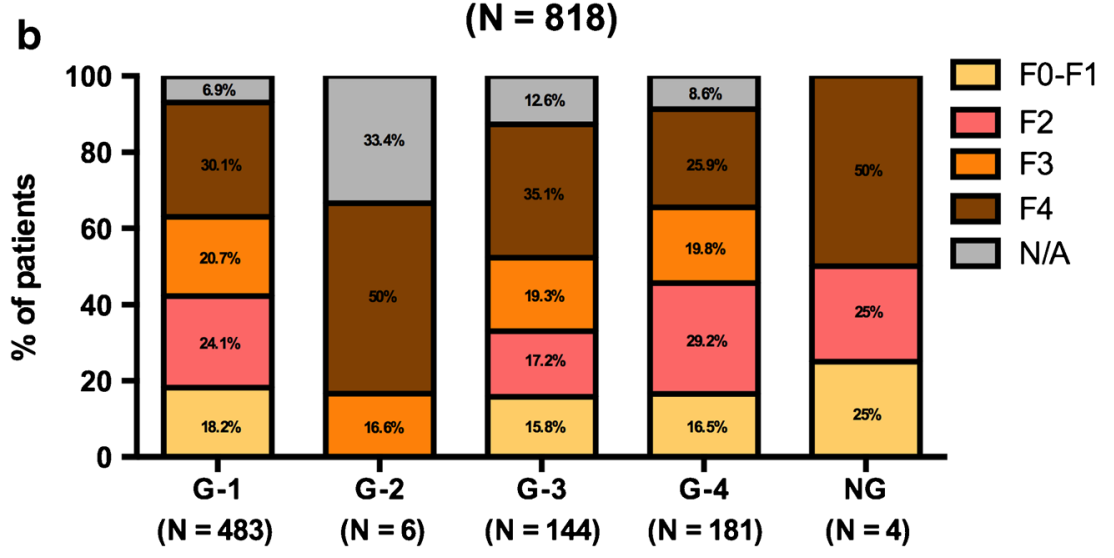

previous treatment experience [25-27]. Therefore, HIV infection should not remain an associated risk factor to achieve a successful HCV treatment outcome in the new DAA era and should benefit from the same treatment regimen and strategies as HCV mono-infected patients. On the other hand, more than $40 \%$ of our population was aged more than 50 years. This establishes a high sensitivity population due to polymedication (including HAART drugs) and age-associated pathologies, supposing a higher drug-drug interaction complicating the management of this population using HCV DAA drugs.

The HCV clinical guidelines identify those HCV-infected patients at the highest risk for severe hepatic complications [7, 8]. The main reason is that this population includes patients in whom HCV therapy provides the most immediate and impactful benefit $[28,29]$. Our study shows that an important burden of the highest priority patients require an immediate treatment implementation to improve life expectancy and avoid both liver and non-liver-related complications. According to liver fibrosis stage, in our study, the proportion of patients with a liver fibrosis stage of F3 or F4 increased to $37.7 \%$, with the highest representation of patients who had failed to respond to a previous treatment. However, the different distribution of the
F4 population according to previous HCV treatment experience was potentially a result of the prioritization of $\mathrm{HCV}$ treatment when non-highly successful drugs were available. $\mathrm{HCV}$ genotype 3 has been considered one of the best scenarios under the Peg-IFN/RBV therapy. Nevertheless, those patients who have currently failed to respond to a previous treatment and with liver cirrhosis staging (35.1\% in our population) do not have a good prognosis [30]. This is because, by applying the treatment regimens currently recommended in this population, the expected SVR rate would be approximately $60 \%$, which is clearly insufficient compared to the SVR rate achieved in the same population in other genotypes. Therefore, this represents a priority treatment population with an expected lower healing rate. Consequently, specific treatment strategies must be investigated in this population.

Our study has several limitations. Firstly, it should be noted that $9.6 \%$ of patients had missing liver fibrosis stage data. Secondly, although the percentage of ungenotyped patients was relatively low (2.6\%), the percentage of HCV genotype 1 patients who were unsubtyped was $36.9 \%$. Nevertheless, the missing data were distributed across all hospitals; thus, the reported liver fibrosis stage and HCV genotype distribution 
could not change significantly. This point supports the fact that the implementation of extra resources is mandatory to obtain the best management and care for HCV infection.

In conclusion, our results reveal the current magnitude of this disease, showing that, during the next few years, HCV treatment should be a mandatory clinical provision in HIVinfected patients. In this situation, acquiring additional resources to proportionate the best clinical care options in this highly sensitive population is a priority. In a public health care system, such as those in Spanish and most European countries, this supposes an important amount of resources to intensify care management in this area.

Acknowledgments We acknowledge Ana Gordon, Patricia Monje, and María Isabel Mayorga for their support in the data collection.

Financial support The HEPAVIR group is the recipient of a Research Network Support Grant from the Fundación Progreso y Salud (Consejería de Salud, Innovación y Ciencia de la Junta de Andalucia; AC-0095-2013, AYUDAS A GRUPOS DE INVESTIGACION). This work was supported by the Ministerio de Sanidad (RD12/0017/0012 and PI15/01017) integrated in the Plan Nacional de I+D+I and cofinanced by the ISCIIISubdirección General de Evaluación and the Fondo Europeo de Desarrollo Regional (FEDER). A.R.-J. is the recipient of a PostDoctoral Research Extension Grant from the Fundación Progreso y Salud (0024-RH-2013 Consejería de Salud, Innovación y Ciencia de la Junta de Andalucia). K.N. is the recipient of a Miguel Servet research grant from the Instituto de Salud Carlos III (grant number CP13/00187).

Conflict of interest We declare no competing interests. The authors or their institutions did not receive at any time payment or services from a third party for any aspect of the submitted work (data monitoring board, study design, manuscript preparation, statistical analysis, etc.).

Contributors A.R. and L.F.L.-C. had full access to all of the data in the study and take responsibility for the integrity of the data and the accuracy of the data analysis.

Study concept and design: A.R.-J., A.G.-V., L.F.L.-C., and A.R

Analysis and interpretation of the data: A.R.-J. and A.G.-V.

Drafting of the manuscript: A.R.-J., A.R., and L.F.L.-C.

Critical revision of the manuscript for important intellectual content: all authors.

Statistical analysis: A.R.-J.

Obtained funding: A.R. and L.F.L.-C.

Administrative, technical, or material support: all authors.

Study supervision: A.R. and L.F.L.-C.

Open Access This article is distributed under the terms of the Creative Commons Attribution 4.0 International License (http:// creativecommons.org/licenses/by/4.0/), which permits unrestricted use, distribution, and reproduction in any medium, provided you give appropriate credit to the original author(s) and the source, provide a link to the Creative Commons license, and indicate if changes were made.

\section{References}

1. Lawitz E, Sulkowski MS, Ghalib R et al (2014) Simeprevir plus sofosbuvir, with or without ribavirin, to treat chronic infection with hepatitis $\mathrm{C}$ virus genotype 1 in non-responders to pegylated interferon and ribavirin and treatment-naive patients: the COSMOS randomised study. Lancet 384:1756-1765

2. Manns M, Pol S, Jacobson IM et al (2014) All-oral daclatasvir plus asunaprevir for hepatitis $\mathrm{C}$ virus genotype $1 \mathrm{~b}$ : a multinational, phase 3, multicohort study. Lancet 384:1597-1605

3. Zeuzem S, Dusheiko GM, Salupere R et al (2014) Sofosbuvir and ribavirin in HCV genotypes 2 and 3. N Engl J Med 370:1993-2001

4. Ferenci P, Bernstein D, Lalezari J et al (2014) ABT-450/rombitasvir and dasabuvir with or without ribavirin for HCV. N Engl J Med 370:1983-1992

5. Afdhal N, Zeuzem S, Kwo P et al (2014) Ledipasvir and sofosbuvir for untreated HCV genotype 1 infection. N Engl J Med 370:18891898

6. Kohli A, Osinusi A, Sims Z et al (2015) Virological response after 6 week triple-drug regimens for hepatitis $\mathrm{C}$ : a proof-of-concept phase 2A cohort study. Lancet 385:1107-1113

7. Recommendations for Testing, Managing, and Treating Hepatitis $\mathrm{C}$ of the American Association for the Study of Liver Diseases (AASLD) and the Infectious Diseases Society of America (IDSA). Available online at: http://www.hcvguidelines.org. Accessed 21st July 2015

8. European Association for the Study of the Liver (EASL) Recommendations on Treatment of Hepatitis C 2014. Available online at: http://www.easl.eu/discover/news/easlrecommendations-on-treatment-of-hepatitis-c-2014. Accessed 21st July 2015

9. Mohd Hanafiah K, Groeger J, Flaxman AD, Wiersma ST (2013) Global epidemiology of hepatitis $\mathrm{C}$ virus infection: new estimates of age-specific antibody to HCV seroprevalence. Hepatology 57: 1333-1342

10. Kim AY, Onofrey S, Church DR (2013) An epidemiologic update on hepatitis $\mathrm{C}$ infection in persons living with or at risk of HIV infection. J Infect Dis 207(Suppl 1):S1-S6

11. Macías J, Melguizo I, Fernández-Rivera FJ et al (2002) Mortality due to liver failure and impact on survival of hepatitis virus infections in HIV-infected patients receiving potent antiretroviral therapy. Eur J Clin Microbiol Infect Dis 21:775-781

12. Merchante N, Girón-González JA, González-Serrano M et al (2006) Survival and prognostic factors of HIV-infected patients with HCV-related end-stage liver disease. AIDS 20:49-57

13. Pineda JA, García-García JA, Aguilar-Guisado $\mathrm{M}$ et al (2007) Clinical progression of hepatitis C virus-related chronic liver disease in human immunodeficiency virusinfected patients undergoing highly active antiretroviral therapy. Hepatology 46:622-630

14. Smit C, van den Berg C, Geskus R, Berkhout B, Coutinho R, Prins M (2008) Risk of hepatitis-related mortality increased among hepatitis $\mathrm{C}$ virus/HIV-coinfected drug users compared with drug users infected only with hepatitis C virus: a 20 -year prospective study. J Acquir Immune Defic Syndr 47:221-225

15. Hernando V, Alejos B, Monge S et al (2013) All-cause mortality in the cohorts of the Spanish AIDS Research Network (RIS) compared with the general population: 1997-2010. BMC Infect Dis 13:382

16. Berenguer J, Alejos B, Hernando V et al (2012) Trends in mortality according to hepatitis $\mathrm{C}$ virus serostatus in the era of combination antiretroviral therapy. AIDS 26:2241-2246

17. Hernando V, Perez-Cachafeiro S, Lewden C et al (2012) All-cause and liver-related mortality in HIV positive subjects compared to the general population: differences by HCV co-infection. J Hepatol 57: 743-751

18. Macías J, Márquez M, Téllez F et al (2013) Risk of liver decompensation among HIV/hepatitis $\mathrm{C}$ virus-coinfected individuals with advanced fibrosis: implications for the timing of therapy. Clin Infect Dis 57:1401-1408 
19. Messina JP, Humphreys I, Flaxman A et al (2015) Global distribution and prevalence of hepatitis C virus genotypes. Hepatology 61:77-87

20. Esteban JI, Sauleda S, Quer J (2008) The changing epidemiology of hepatitis C virus infection in Europe. J Hepatol 48:148-162

21. Edlin BR, Carden MR (2006) Injection drug users: the overlooked core of the hepatitis C epidemic. Clin Infect Dis 42:673-676

22. Davies A, Singh KP, Shubber $Z$ et al (2013) Treatment outcomes of treatment-naïve Hepatitis $\mathrm{C}$ patients co-infected with HIV: a systematic review and meta-analysis of observational cohorts. PLoS One 8:e55373

23. Konerman MA, Mehta SH, Sutcliffe CG et al (2014) Fibrosis progression in human immunodeficiency virus/hepatitis $\mathrm{C}$ virus coinfected adults: prospective analysis of 435 liver biopsy pairs. Hepatology 59:767-775

24. Pineda JA, Aguilar-Guisado M, Rivero A et al (2009) Natural history of compensated hepatitis C virus-related cirrhosis in HIVinfected patients. Clin Infect Dis 49:1274-1282

25. Sulkowski MS, Naggie S, Lalezari J et al (2014) Sofosbuvir and ribavirin for hepatitis $\mathrm{C}$ in patients with HIV coinfection. JAMA 312:353-361
26. Sulkowski MS, Eron JJ, Wyles D et al (2015) Ombitasvir, paritaprevir co-dosed with ritonavir, dasabuvir, and ribavirin for hepatitis $\mathrm{C}$ in patients co-infected with HIV-1: a randomized trial. JAMA 313:1223-1231

27. Osinusi A, Townsend K, Kohli A et al (2015) Virologic response following combined ledipasvir and sofosbuvir administration in patients with HCV genotype 1 and HIV co-infection. JAMA 313: 1232-1239

28. Mira JA, Rivero-Juárez A, López-Cortés LF et al (2013) Benefits from sustained virologic response to pegylated interferon plus ribavirin in HIV/hepatitis $\mathrm{C}$ virus-coinfected patients with compensated cirrhosis. Clin Infect Dis 56: $1646-1653$

29. van der Meer AJ, Veldt BJ, Feld JJ et al (2012) Association between sustained virological response and all-cause mortality among patients with chronic hepatitis $\mathrm{C}$ and advanced hepatic fibrosis. JAMA 308:2584-2593

30. Ampuero J, Romero-Gómez M, Reddy KR (2014) Review article: HCV genotype 3-the new treatment challenge. Aliment Pharmacol Ther 39:686-698 